\title{
Badua, diosa o dios, y los ritos del toro de San Marcos
}

\author{
Bandua, goddess or god, and the rites of San Marcos' bull
}

\author{
F. Javier Burgaleta Mezo*
}

\begin{abstract}
RESUMEN
En este artículo discutimos, en primer lugar, el carácter atribuido a Bandua como divinidad masculina, asimilable tanto a Marte indígena como al Genio, en base a una pátera de la colección Calzadilla de Badajoz y procedencia incierta (quizás $S$. Cosmado, en Mangualde, Portugal), en la que aparece una representación que entendemos es de esa divinidad, como una posible Tutela claramente femenina con cornucopia y otros detalles. En segundo lugar, analizamos la cuestión de los orígenes del rito del toro de San Marcos, en una fiesta cuyo origen Olivares Pedreño (1997) remonta a épocas primitivas, hasta establecer un vínculo con Bandua, asimilado a Marte indígena y al toro. Una posición seguidora en parte de Caro Baroja. Nosotros, sin embargo, la contrastamos con las problemáticas generales de la fiesta del toro en época moderna, subrayando su relación con determinadas cuestiones estructurales.
\end{abstract}

PALABRAS CLAVE: Bandua, Tutela, ritos del toro, supervivencias, realidades estructurales.

\begin{abstract}
In this article we discuss, in the first place, the character attributed to Bandua like masculine divinity, assimilable as much to indigenous Mars as to the Genius, based on a patera of the collection Calzadilla of Badajoz and uncertain origin (maybe $S$. Cosmado, in Mangualde, Portugal), in which a representation appears that we understand it is of that divinity, like a possible one clearly feminine Tutela with cornucopia and other details. In second place, we analyze the question of the origins of the rite of San Marcos' bull, in a ritual whose origin Olivares Pedreño (1997) goes back to primitive times, until establishing a bond with Bandua, assimilated to Indigenous Mars and to the bull. A position that is follower partly of Caro Baroja. For us, however, contrast with the general problems of the ritual of the bull in modern time, underlining their relationship with certain structural questions.
\end{abstract}

\section{KEYWORDS:}

Bandua, Tutela, rites of the bull, survivals, structural realities.

* Depto. Ciencias de la Antigüedad. Facultad de Filosofía y Letras. Campus Universitario. 10071 Cáceres. E-mail: fjburgal@ nex.es 
Señalamos en otro lugar, a propósito del difícil tema de la supervivencia de mitos y ritos de raíces remotas, algunas cuestiones relativas a la interpretación de algunos rituales en la Península Ibérica y su problemática ${ }^{1}$, en concreto la propuesta de interpretaciones de Olivares Pedreño sobre el dios —o la diosa- Bandua y los ritos del toro de San Marcos. Entonces cotejábamos su artículo especialmente con el estudio del mismo ritual realizado por Rodríguez Becerra. Queremos volver ahora sobre ese tema, para apuntar determinadas cuestiones con más detalle, repasando las propuestas de este investigador con algún conocido documento que quizás haya pasado por alto y ayude a ilustrar algo de la naturaleza de esta divinidad, por un lado. Y por otro, señalar otros aspectos ya no relacionados con la citada divinidad, pero que vuelven sobre el origen el rito del toro de San Marcos y las problemáticas generales de la fiesta del toro en medio de la polémica de las supervivencias de ritos primitivos en la cultura popular de la Europa moderna.

\section{CUESTIONES SOBRE LA NATURALEZA DE BANDUA}

En un sugerente artículo, y luego, en su enjundiosa monografía sobre las divinidades célticas, nos presenta Olivares Pedreño (1997 y 2002) determinadas cuestiones sobre Bandua, divinidad que entendía se podía asimilar a Marte indígena y a Consus (2002: p. 157). Una propuesta que él mismo admitía como delicada en ciertos extremos. En la primera de las referidas obras se sostenía la relación entre el rito del toro de San Marcos y Bandua (1997: p. 213), asunto que desarrollaremos posteriormente. La relación entre Marte indígena con el toro se establecía en base a la estatuilla procedente de la región pirenaica que representa a Marte con un toro en la coraza (1997: p. 211); también con el epígrafe de Montariol (S. Vitor, Braga), en el que se alude con el epíteto Tarbucelis, que podría relacionarse con el nombre celta del toro (Tarvos), y, finalmente, con otros ejemplos muy distantes, procedentes de Britania y otros lugares de Centroeuropa. Por otra parte, la equivalencia entre el «Marte indígena» y el dios Cosus la considera comúnmente admitida, según atestiguaría una dedicación a Cososo deo Marti (cf. 1997: nota 43, p. y 2002: p. 157 y nota 152). Sin embargo, la identificación Marte Bandua no está exenta de dificultades. Como él mismo indica (1997: p. 212; 2002: p. 157), si la relación entre las dos divinidades mencionadas ha sido usualmente aceptada, la asimilación de Bandua con el «Marte indígena» y con Cosus no ha sido hasta hoy admitida por la mayoría de los estudiosos y él la establece en base a la inscripción de Rairiz de la Vega, dedicada a Martis socio Banduae, de autenticidad disputada ${ }^{2}$, procedente de un punto que estaría en la línea de intersec-

1 F. Javier Burgaleta Mezo, «Problemas de la supervivencia de los mitos de la Hispania antigua» en Martos Núñez, Eloy, y Suárez Muñoz, Angel, Lectuario 2003, Badajoz, 2003, pp. 29 a 42.

2 A. Rodríguez Colmenero apunta diversas razones para considerarla auténtica. Pero el mismo Olivares Pedreño, en su nota 49 (1997: p. 220), recoge como Hübner la da como falsa o mal leída (CIL II $\left.215^{\star}\right)$; J. Lorenzo y F. Bouza se inclinan por una mala lectura («Inscripciones romanas votivas de la provincia de Orense», CEG 20, 1965, p. 156, n. ${ }^{\circ} 87$ ). J. C. Rivas pensaba que el texto era inusual en ese ámbito geográfico, desordenado e incompleto, considerándolo falso hasta que se expusieran nuevos argumentos. 
ción entre las zonas donde se rendía culto a una y otra divinidades -Bandua y Cosus-. La argumentación termina en la distribución geográfica de los epígrafes, excluyentes entre sí (2002: p. 158).

Olivares Pedreño (2002: p. 155) interpreta a Bandua vinculándolo a la protección de las entidades sociales que aparecen asociadas en los epígrafes a él dedicados. Algo, recuerda, ya conocido por los investigadores: que en el territorio lusitano galaico, Bandua es la divinidad indígena que con mayor frecuencia se cita junto a epítetos referidos a vici, pagi o castella. Por lo que se puede concluir su especial relación con entidades sociales indígenas de segundo rango. Por el contrario, no se asociaría con grupos familiares, clánicos o tribales ${ }^{3}$. Cuestión ésta delicada.

Si bien entendemos que la identificación que propone entre Bandua y Marte es una identificación funcional, semejante en su papel a la del Genio, ésta ha de quedar ahí. Pues en efecto, habla de ella como divinidad masculina de carácter militar ${ }^{4}$. Sin embargo, si consideramos un documento que Olivares Pedreño ignora, al menos parcialmente, como veremos, la identificación entre Bandua y Marte podría quedar en suspenso. Según indica J. M. Blázquez Martínez (1983: p. 263 y 295, e ilustración n. ${ }^{\circ} 159$ ), hay una representación identificable con Bandua Araugelensis por la inscripción asociada, en la que se lee Band(i) Arugel(ensi) en una pátera de plata dorada de la Colección Calzadilla de Badajoz, que procedería probablemente de S. Cosmado (Mangualde, Portugal), o bien, de un lugar indeterminado de Cáceres (como propone él mismo en otro lugar). En ella la divinidad aparece en el centro, rodeada de un arbusto, unos peñascos y de cuatro aras, tres de ellas encendidas. La figura de la diosa viste manto y sostiene en su mano izquierda una cornucopia y en su derecha una pátera. Está tocada con corona mural. Para Blázquez, la diosa tiene todos los atributos de la Fortuna romana, que sería, según el mismo autor, protectora de la familia de la gens, a la que seguramente hace referencia el adjetivo que acompaña al nombre. Igualmente señala Blázquez intutitivamente que la asimilación de una diosa del panteón helenístico-romano por los indígenas explica la frecuencia de deidades de las mismas características atestiguadas en la Península, deidades que aparecen en los nombres de muchas Tutelae, a los que siguen epítetos indígenas, que las aras ofrecen con mayor densidad que en otras provincias del Imperio. $Y$ que tales dioses son frecuentes en época de los Antoninos o de los Severos y poseen un carácter sincretístico. Así

3 Remitiéndose a Albertos (1977: p. 21). Esto mismo ya lo había advertido De Hoz (1986: p. 41), cuyas consideraciones sobre la naturaleza de la divinidad expondremos más abajo; entidad protectora y tutelar —en lo que coincide con la apreciación de Blázquez (cf. infra.) —, y ligada a «comunidades humanas».

4 Olivares Pedreño (2002: p. 167). «En resumen, la vinculación de Bandua a los Genios romanos o a Marte vendría dada por su carácter tutelar de las poblaciones indígenas, función que aún conservaría reminiscencias del papel que, probablemente, en los momentos previos a la conquista romana habría desempeñado como dios defensor de la comunidad en tiempos de guerra». Y luego (Olivares Pedreño 2002: p. 168): «Paralelamente a la anulación del poder político de los castella y la centralización del mismo en determinados oppida, el carácter público y guerrero de divinidades como Bandua fue perdiendo gran parte de su sentido conservando un carácter de dios tutelar de los individuos residentes en los uici, pagi y castella, entendidos ya únicamente, como grupo social.» 
mismo, insiste en que por la referida inscripción se probaría que todas las deidades indígenas hispanas en cuyo nombre entra el radical Band-, que deriva del indoeuropeo bhenelh-, serían deidades asimiladas a Fortuna y que son protectoras de la gens, al igual que las Tutelas. Sin embargo, sobre al carácter de la representación, De Hoz (1986: p. 39-40), al hilo de sus argumentaciones sobre Bandua - Bandue como teónimo que luego desarrollaremos, y remitiéndose a un estudio de $\mathrm{A}$. Blanco (1959) considera que esta representación debe ponerse en relación con un problema relacionado con la doble percepción en la religión romana entre una vertiente popular que desarrolla creencias en divinidades impersonales que continúan el culto primitivo a los objetos naturales, fuentes, árboles o piedras, pero separadas ahora de esos objetos como genios que ya no se confunden con su lugar de residencia.

Curiosamente, Olivares Pedreño (2002: p. 153) recoge esta inscripción sobre pátera ignorando la lectura Band inicial, y leyendo sólo la segunda parte $A R A U$ GEL(...); indica su ubicación en la Colección Calzadilla de Badajoz y propone la relación del epíteto Araocelum, remitiéndose a Albertos (1985: 472) y Alarcâo (1989: 307 y 307), para quienes podría referirse a un castellum Araocelum ubicado en el área del actual Viseu, según se deduce de la inscripción en la que se menciona a unos castellani Araocelenses en el citado S. Cosmado; e ignora cualquier cuestión sobre su iconografía. Posteriormente (Olivares Pedreño 2002: p. 166) vuelve a mencionar esta pieza en relación con la existencia de un posible castro en S. Cosmado (Mangualde).

Por tanto, si tomamos en cuenta la representación de Bandua antedicha y la podemos asociar con la inscripción que la acompaña, y si ésta es coherente con el

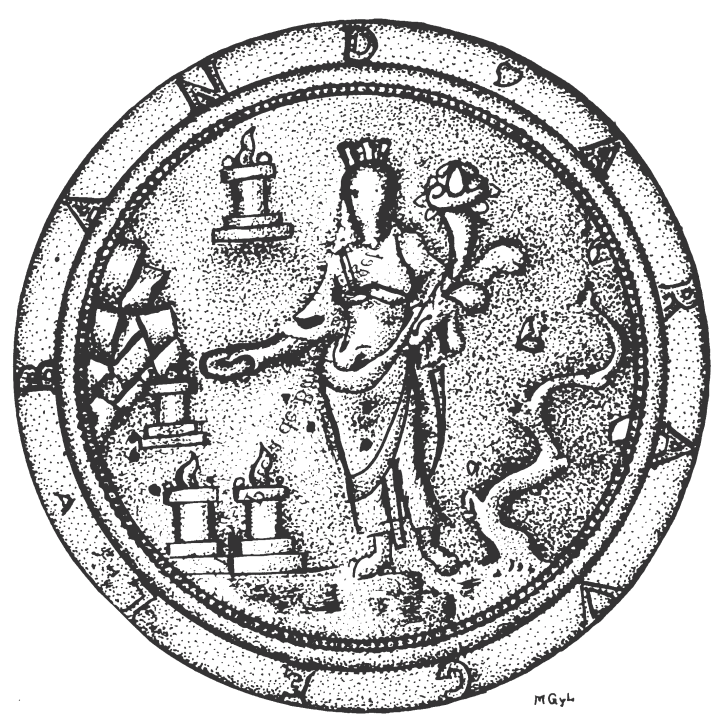

Fig. 1. Dibujo de la pátera de la Colección Calzadilla de Badajoz, procedente probablemente de S. Cosmado (Mangualde, Portugal), según J. M. Blázquez Martínez (1983: ilustración n. ${ }^{\circ}$ 159). 
carácter de la divinidad, lo que cabe suponer en el contexto de la misma, Bandua sería una divinidad femenina, asociable a Tutela, como propuso Blázquez, y no a Marte ni al Genio. Quedaría pendiente la cuestión del carácter de esa divinidad femenina, de su naturaleza y de clase de protección que ofrece: militar o de otro tipo, cuestión que puede entroncar con el papel protector de las comunidades por parte del Marte indígena. Y la entidad social que protege.

De Hoz (1986: p. 36-7), sin embargo, sostiene una postura muy distinta sobre el carácter de la divinidad. Aprecia así como en cierto número de inscripciones el nombre de la divinidad va acompañado de un epíteto en - $c o$, en otras de un epíteto compuesto con -briga utilizado como adjetivo masculino; y menciona la inscripción de Rairiz de la Vega (Orense), que señala como dudosa, a Deo Banduae. A continuación recuerda la dedicación a Bandua Lanobrigae y la susodicha pátera de plata de la colección Calzadilla, casos ambos en los que parece estaríamos ante una divinidad femenina. Esta aparente contradicción la resuelve advirtiendo que en la mayor parte de los testimonios Bandue va acompañado de un epíteto que lo define, y deduce de ello que no se trate del nombre propio de una divinidad específica sino que se trataría de un nombre común, del tipo de deus o tutela o lar, que designaba en la lengua lusitana a diversas deidades, concretadas por su epíteto que las definía. Recapitulando (De Hoz 1986: p. 39), Bandue es probablemente un nombre común del campo religioso lusitano, traducible por «divinidad», aunque posiblemente con connotaciones más precisas a las que ya nos hemos referido al mencionar su vinculación con determinados tipos de entidades sociales y organizativas indígenas; que se usó entre los lusitanos en sentido estricto y entre los galaicos de la zona entre el Duero y Miño.

Restarían otros aspectos de menor importancia por comentar de este conjunto epigráfico de fuerte sabor indígena y de época romana. Así, por ejemplo, en la recopilación de inscripciones dedicadas a la divinidad que ofrece Olivares Pedreño, e insistiendo en parte en un aspecto comentado por De Hoz, para lo que propone un análisis lingüístico de concordancias, encontramos a la divinidad nombrada con un significativo número de variantes, lo que también podría ser indicativo, a nuestro entender, de un indigenismo cuyo aislamiento intersticial no alcanza a nombrar a la divinidad de la misma y exacta manera. Aspecto que nos devuelve al de tantos otros intrínsecos a esa epigrafía — de ambiente indígena y época romana-, y a otros problemas de la misma, como son los de las organizaciones sociales que lo generan. Por esta senda llegamos a la cuestión de la extensión del culto respecto del panorama étnico, observando entonces dos cosas: que es en parte aproximadamente lusitano; pero sólo en parte, por lo que caben deducirse a su vez dos cuestiones: o que el culto era compartido por varias etnias peninsulares antes de la influencia romana, lo que no es improbable, o que sufrió un proceso de difusión en época romana, ligado quizás a un posible desleimiento de esas entidades organizativas indígenas por la nueva estructura política romana, aunque en ellas se conservasen sus modos de organización social. Así, resta por explicar la presencia fuera del área de distribución más habitual, que son las provincias de Orense y Sierra de la Estrella, de un epígrafe procedente de Mezquitilla (Toledo) (De Hoz 1986: p. 36), muy alejado de esa distribución más habitual, incluso las procedentes 
de Trujillo y Madroñera dedicadas a Banduae Roudeaeco, que estarían, en cualquier caso, en territorio vetón (Burgaleta 2001).

\section{EL RITO DEL TORO DE SAN MARCOS}

Como hemos dicho, el interés en volver sobre estos trabajos de Olivares Pedreño respondía, en primer lugar, a señalar esa representación de Bandua, de donde cabe identificar rasgos de su carácter, y si la interpretación es correcta, hemos de distanciarla de su asimilación a Marte. Y la segunda cuestión que ahora iniciamos es el tema del rito del toro de San Marcos, ya no asociable estrictamente a Bandua, sino entendido como un rito sobre el que cabe plantear una supervivencia en términos más generales; pues en palabras de dos estudiosos como Caro Baroja y Rodríguez Becerra (2000: p. 221), sorprende su sabor terriblemente pagano, que principia en una coincidencia en el calendario que Olivares Pedreño pasaba por alto, pero sí identificaban aquellos otros investigadores: la fiesta de las Robigalia, en la que, paradójicamente, y siguiendo sutiles tramas, pudiera aparecer Marte como divinidad protectora de los campos.

Nuestro autor, tras introducir el problema exponiendo las conclusiones a las que había llegado Caro Baroja, da un repaso a distintos documentos que hacen referencia a dicho rito en época moderna, para, a continuación, revisar los testimonios epigráficos de época romana que hacen referencia a Marte indígena ${ }^{5}$, a Bandua y a Consus, divinidades que pueden asimilarse a la primera. Si Julio Caro Baroja, en el estudio que dedicó al tema y que parece ser uno de los puntos de partida de este otro acometido por Olivares Pedreño, no se mostraba del todo satisfecho con las conclusiones a las que había llegado, adoleciendo de no haber encontrado esa «conexión satisfactoria» que creía Caro Baroja faltaba a su análisis ${ }^{6}$, el trabajo de Olivares Pedreño da la impresión de no haberla hallado tampoco, al menos, de manera totalmente satisfactoria, pues como veremos, el ajuste entre ese conjunto de epígrafes y el culto al toro no es tan evidente como nos gustaría poder afirmar.

Rodríguez Becerra, quien, como veremos, realiza un acertado estudio del ritual en época moderna, proporciona un panorama geográfico bien distinto del conjunto de epígrafes dedicados a Bandua, y pondera sus posibles raíces franciscanas, recordando el ambiente milagrero de la época, y no deja de mencionar las coincidencias con la fiesta de las Robigalia (Rodríguez Becerra 2000: p. 224), al igual que Caro Baroja, en las que dice, se incluiría un toro, lo que no documentamos en

\footnotetext{
5 Marte con distintos epítetos en la documentación como Tileno, Tarbucelo, Carieco, y en las dedicaciones en dativo, aparecen como Marti Cariocieco, en Tuy (Pontevedra); Mar() Cari(), Mar[ti Cari[eco, Marti Tarbuceli, Marti Tileno, Tilleno, Marti Sagato, Marti Boro, etc.

6 Tras haber propuesto, en Ritos y mitos equívocos, un paralelismo con otras celebradas en honor a Dionisos, en particular ciertas festividades celebradas en Arcadia [Asia Menor], pues en ambas se daba una identificación del dios con un toro, implicando una selección del toro que encarnaba al santo y al dios en una fiesta anual, en la que el animal era conducido al templo, y se daba una relación especial con las mujeres y con el vino.
} 
las fuentes antiguas. Ambos autores, fuera de temas de detalle, se remiten a una realidad estructural. El mismo Caro Baroja (1991: p. 183), señala como la fiesta de San Marcos (el 25 de abril) es el comienzo de los movimientos pastorales, iniciando el ciclo de mayo, «mes de las fiestas y expansiones amorosas». Si la fiesta se celebra en muchos sitios como parte de unas fiestas agrarias, precisamente esas zonas donde se documenta el rito con toro son, en muchos casos, aquellas donde se han conservado reses de lidia, y donde el roce con las mismas es un elemento más de la vida económica. Se trata de unos ritos celebrados en pueblos donde determinadas actividades pastoriles tienen una importancia capital, donde el manejo del ganado es un elemento económico esencial, y donde el simbolismo del toro sigue jugando difuso pero evocador.

Con la fiesta y procesión de San Marcos se pretendía conseguir según Rodríguez Becerra (2000: p. 221), entre otros objetivos, como antes se hiciera entre los romanos antiguos - en clara relación de la fiesta con las Robigalia-, la protección para cosechas y animales, y también lluvia mediante rogativas. Se consideraba, así mismo, que en esta fecha terminaba el invierno y comenzaba el verano -en una concepción dual del año, propia de agricultores y ganaderos-, y era, por tanto, el momento de hacer ciertas siembras. Se tomaba así mismo su fiesta como inicio del cálculo sobre las predicciones de lluvia para el año, las denominadas «cabañuelas». Todo indica que el evangelista San Marcos llegó a constituirse en un referente para agricultores y ganaderos. Rodríguez Becerra (2000: p. 224), afirma, por tanto, que es lógico pensar, aunque carecemos de datos para afirmarlo, que a la hora de fijar una fiesta que cristianizara la fiesta romana de las Rubigalia que incluían un toro, se escogiera a este santo cuya vinculación con el toro era manifiesta ${ }^{7}$.

Respecto de la fiesta de la Robigalia, fiestas del dios Robigus, instituida por el rey Numa, se celebraba el 25 de abril, momento en que florece el trigo y se forma la espiga. El fenómeno de la «herrumbre» o roya parda del trigo, se designa en latín por la palabra robigo ${ }^{8}$. Se celebra mediante una procesión que se dirigía a un lucus Robigi, en el quinto miliario de la vía Claudia, y en ella oficia el flamen Quirinalis, que es el ministro de Marte entre los sabinos ${ }^{9}$. Se le sacrifica una oveja y un perro. Ovidio (Fast. 4, 907-42) da una descripción de la fiesta, explicándola, quizás con deformaciones, y menta el discurso en el que el flamen pide que la herrumbre (robigo) se eche sobre las armas de la guerra, pero que respete las espigas y las herramientas de labranza para que nunca falten al labrador las espigas con que obsequiar anualmente a la divinidad (Guillén 1985: p 314). Hild (1911) conjetura con Mommsem si realmente Robigus era menos una personalidad distinta antes que un aspecto personificado de Marte rústico, y recuerda la plegaria recogida en Catón (Agr. 141) por la que el campesino solicita a Marte protección

7 La identificación del santo con el toro se produciría por serie de elementos coincidentes en su martirio que señala Voragine.

${ }^{8}$ Del radical robus = rufus, rojo; Guillén (1985: p. 203), la llama ñubla, y se refiere también al tizón y a la royuela o cornihuela. Cf. sobre todo esto en Hild (1911).

9 Guillén (1985: p. 203-4) indica que Quirino es una forma de Marte. Robigus además parecería una indigitatio de Marte. 
para sus cultivos de las intemperancias. Dürrbach (1911) recuerda que este Marte Silvanus es invocado por los patres y pastores como protector de sus ganados, y es análogo a Apolo Nómios o Napaîos. El mismo indica que en las Robigalia se asociaba a Robigo, en una función que en Rodas estaba dedicada a Apolo erythíbios. Curiosamente, encontramos un Marte en esa faceta de defensor de los campos en las fiestas de las Robigalia, como apunta Dürrbach (1911). Sin embargo, según los compendios no encontramos ningún toro en ella, al contrario de lo que afirman estos estudiosos. Pero, fuera de Roma, podría tratarse de una fiesta de carácter popular, en la que aparece Marte como defensor de los campos, y bien pudiera ser una fiesta relacionada con ese aspecto estructural que se ha mencionado: momento clave para la supervivencia de los grupos, lo que es coherente con la representación de Bandua sosteniendo la cornucopia, símbolo de abundancia.

Otra cuestión es que la geografía de la fiesta de la España moderna que ofrece Rodríguez Becerra (2000) ya no coincide con el conjunto de epígrafes dedicados a Bandua. Algo ya mencionado por el propio Olivares Pedreño ${ }^{10}$. Para Rodríguez Becerra la distribución de la fiesta responde claramente a unas condiciones ecológicas y económicas, documentándose en los núcleos rurales de las zonas serranas, que para Extremadura son preferentemente Cáceres, y para Andalucía, las de Granada, Almería, Córdoba y Jaén, mientras casi no aparece en las llanuras del valle del Guadalquivir y la Campiña. Pero además, se atestigua el culto del santotoro incluyendo la presencia de este animal en lugares de las diócesis de Murcia durante los siglos XVI-XVII, todos ellos muy alejados del Occidente hispano. Sin mentar otras muchas ermitas y altares de las que fue titular el Santo en otros muchos puntos de las diócesis de Castilla la Nueva ${ }^{11}$. Y más adelante da noticia de otra ceremonia documentada en Baeza ya en 1449 como voto perpetuo para librar a la misma de una plaga de langosta: "ésta cesó y la ciudad se comprometió a ofrecerle anualmente al santo un toro y posteriormente donarlo como limosna a los pobres, lo que a su vez dio lugar a un fenómeno de emulación en los lugares ve-

10 En los casos de Alosno y Castillo de las Guardias, en Huelva, o de Casas del Monte, en un documento de inicios del siglo xIX en el que se habla de la fundación de una cofradía instaurada en honor de San Marcos, creada en 1669, y que funcionó hasta la prohibición del rito en 1753; el mismo Olivares (1997: nota 34, p. 208) explica cómo se importó e instauró, y cómo tuvieron que aprender los cofrades los métodos de ejecución de la liturgia, yendo a informarse el párroco de Pozuelo de Zarzón a Mirabel. Esto implica -observa Olivares Pedreño- que en Mirabel se celebraba desde mucho antes. Lo que no sabemos es cuánto antes (cf. sobre este mismo aspecto, Rodríguez Becerra 2000: p. 230). Antes, Olivares Pedreño (1997: nota 34, p. 207) cita otro caso en el que el Obispo de Ávila niega a los habitantes de un pueblo permiso para introducir el culto, lo que para Olivares deja el asunto dentro de la ambigüedad «pues no confirma si en el mencionado pueblo existía ya una tradición referente al toro y lo que se intentaba era hacerla coincidir con la festividad de San Marcos, o si no existía dicha tradición y sólo se intentaba importarla de otros lugares", siendo posible plantearlo en los términos que él dice, o más bien cabe situarla en otros semejantes a los anteriores que hemos visto: es decir, que se trate de un fenómeno de difusión por modas de cultos.

11 «En cualquier caso hay que ponderar la importancia de la devoción a este santo comparándola con otras de la misma época; así, si tomamos el dato de la titularidad de las ermitas dedicadas a la Virgen María y a los santos Sebastián y Roque en Castilla la Nueva a finales del siglo xvı, eran muy superiores a las de San Marcos; tampoco resiste la comparación con San Sebastián y San Fabián en Extremadura a finales del siglo XVIII» (Rodríguez Becerra 2000: citando a Christian 1991: 93). 
cinos $^{12}$. «En la actualidad -escribe nuestro autor- sólo se celebra en Andalucía procesión con toro en el pequeño pueblo de Ohanes (Almería), localizado en la vertiente sur de Sierra Nevada. En esta fiesta cinco toros enmaromados con una o dos cuerdas son humillados por la fuerza hasta siete veces en el recorrido procesional del santo" (id. p. 233). No olvidemos que la obra de éste autor estudia tan sólo los rituales y fiestas de Andalucía, por lo que queda pendiente de confirmar su extensión a otras zonas en la España moderna.

El mismo Rodríguez Becerra apunta las relaciones franciscanas de la fiesta: Brozas era sede de un convento franciscano desde 1544 que funcionaba como cabecera de la provincia franciscana de San Miguel, en donde cada tres años tenía lugar el capítulo provincial de la orden. La legendaria relación de Francisco de Asís con los animales, así como de San Antonio de Padua, y con ellos, la de los miembros de su orden, es otro argumento no despreciable, que se confirma con la actitud general de los miembros de la orden hacia tal culto $^{13}$, y luego señala a esta misma orden como protagonista de su difusión ${ }^{14}$. La postura de los franciscanos hacia la fiesta, tal como ellos mismos nos lo transmiten, es notablemente distinta del resto de noticias y actitudes implícitas hacia la misma emanada de los textos de ilustrados. Salvo el testimonio de D. Luis de Zapata ${ }^{15}$, aparentemente un laico que no muestra indicios de reprobación hacia la fiesta y relata sorprendido el milagro, el resto critican lo que es una festividad efectivamente muy popular y arropada quizás por esos frailes, los más próximos al pueblo y sus gustos. Hay una notable diferencia en la descripción de la fiesta por un fraile, para quien es un milagro ${ }^{16}$, frente a

12 «Y viendo las demás villas y lugares de su Comarca [Baeza] el remedio tan milagroso, hicieron la misma promesa y voto. De donde se originó la costumbre que en algunos lugares ha quedado de llevar un toro en la procesión el día de San Marcos» (citando a Ximena Jurado, M., Catálogo de los obispos de las Iglesias catedrales de la Diócesis de Jaén y Annales Eclesiásticos deste Obispado, Madrid, 1654, p. 402).

${ }_{13}$ Recordemos el episodio de San Francisco con el lobo de Gubbio, al que amansó, o el de la oveja que le habían regalado; así mismo, San Francisco de Padua y la mula, el más famoso de los atribuidos al monje portugués, miembro de la orden franciscana y doctor de la iglesia, y con el que algunas veces se le representa. Retado por un incrédulo campesino a que demostrase el misterio de la eucaristía, se dice que la mula hambrienta del campesino fue a arrodillarse ante la Hostia que sostenía San Antonio y no ante el pasto fresco que le ofrecía su amo. Recordemos que algunos de los documentos de tono apologético son de un Fray Francisco de Coria, muy posiblemente monje franciscano (Olivares 1997: nota 34, p. 207-08). Y más adelante (p. 219, nota 5), comenta como efectivamente parece ser que la localidad extremeña de Brozas pueda establecerse el origen del ritual, pues se celebraría en ella desde el siglo xv. Más adelante (id. p. 226), «controversia acerca de la naturaleza milagrosa o diabólica del comportamiento ritual de un toro que año tras año procesionaba mansamente junto a San Marcos en la villa de las Brozas, en donde cada tres años tenía lugar el capítulo provincial de los franciscanos por lo que no es arriesgado pensar que este lugar fuera el centro de irradiación del ritual por toda la península.».

14 Id. p. 229: «En este proceso hay que tener muy en cuenta a los frailes franciscanos, la orden más populista y extendida, pues en los tiempos modernos representaban una cuarta parte de todas las casas masculinas de frailes y monjes de España, que apoyada en una amplia red de conventos han supuesto uno de los más poderosos agentes de difusión de ideas, noticias y hasta de capitales, a través de predicaciones, misiones populares, petición de limosnas y el continuo movimiento e intercambio de frailes entre conventos.»

15 Recogido en Olivares Pedreño (1997: nota 34, p. 207).

16 Cf. supra, y en particular la nota 45. El mismo Rodríguez Becerra (2000: nota 40, p. 219) «se discutía si la repentina mansedumbre del toro era obra de Dios o del diablo», y «Los franciscanos (...), consideraron siempre el ritual del amansamiento del toro como hecho milagroso, frente a otros teólogos que 
las acusaciones que vierten sus detractores, quienes efectivamente consiguieron acabar con ella por las erróneas interpretaciones y maledicencias que provocaba ${ }^{17}$, aun no llegando a describir otros extremos, como los que presenta Velázquez Gaztelu, historiador y cronista de Sanlúcar de Barrameda, cuando se refiere a las fiestas suprimidas y cita las del toro de San Marcos: «Éste se lidiaba después delante de la puerta de la Iglesia y se venía a convertir la procesión eclesiástica en pura ridiculez y profanidad, llamada más a esto la gente que a la invocación de las divinas misericordias „18; siendo esto último algo más parecido a lo contemplado por quien estas líneas escribe en la celebración al santo de Ohanes en abril de 2001, donde había antes que nada lucha con el toro, el cual, en diferentes puntos, era obligado a humillarse por la fuerza, que milagro o conducción mansa. Incluso, se nos recuerda en otro lugar, se ayudaba al milagro emborrachando al animal ${ }^{19}$.

Las diferencias entre ambas exposiciones nos presentan dos extremos antitéticos que nos permiten abordar una última valoración. Si nos detenemos en analizar en qué consiste el ritual, podríamos admitir que, fuera de ser llamado en nombre del santo y en la identificación del animal con el mismo San Marcos ${ }^{20}$, éste estriba en separar un animal de la vacada y conducirlo fuera de ella, paseándolo en procesión, punto sobre el que volveremos luego. Fuera de este aspecto potencialmente pagano, o mejor todavía, popular —en tanto no hemos llegado al asunto de sus orígenes-, que apreciaban los detractores como el propio padre Feijoo y otros comentaristas religiosos, lo encontramos introducido en la liturgia cristiana en tanto el culto lo oficia y dirige un sacerdote, lo que podría distinguirlo de otras festividades populares, de carácter más carnavalesco, como las botargas, casca-

se inclinaban por la existencia de un pacto diabólico. No debe pasarse por alto la especial relación entre el fundador de la orden, San Francisco, y los animales.». También podemos remitirnos otra vez al texto recogido por Olivares Pedreño (1997: nota 34, p. 207-08).

17 Por ejemplo, las que escribe el padre Feijoo (recogido en Olivares Pedreño 1997: nota 34, p. 207): «(...) á veces el toro no obedece a la llamada del Mayordomo de la Cofradía, en cuyo caso, los del pueblo dan por sentado que el Mayordomo es de prosapia judaica. La segunda, que acabadas las Visperas, conducen los cofrades al Toro por las calles, y le hacen entrar en casas del Lugar. Sucede que el toro se resiste a entrar en esta, ó aquella casa, ó porque vé algún objeto, que le espanta, ó por capricho, originando de alguna, entre innumerables causas de incógnito, que pueden influir en ello; porque quien averiguará la impresión, que el encuentro de varios objetos puede hacer en su imaginativa? Pronuncian luego, como si lo huviesen oído á un Oraculo, que á aquella casa, ó habitadores de ella, amenaza alguna proxima calamidad»; y más adelante «(...) estaba el toro en un corral, de donde fue a sacarle el cura revestido, y con todo el aparato de la Iglesia (...); pero aunque le llamó repetidas veces con el nombre de Marcos, el Toro no respondió, sino con bufidos y ademanes de acometer».

$18 \mathrm{Y}$ otros usos en la misma fiesta p. 234, nota 14.

19 El mismo Rodríguez Becerra (2000: p. 225, nota 6) «Como ya dijimos, el Dr. Laguna, médico y botánico, en la traducción y comentarios a la obra de Dioscórides Materia medicinal (1555) obra de consulta durante más de cien años, cita el ceremonial del toro de San Marcos, cuya temporal mansedumbre explica por la borrachera que le provocaban al animal (remitiéndose a Feijoo, Fr. B.G.: Teatro crítico universal o Discursos varios en todo género de materias para desengaño de errores comunes... Madrid, 1781 (1736), tomo VII, discurso 80, págs. 205-225: en su p. 220; y Fernández Vailin, A.: Cultura científica de España en el siglo xVı Discursos leídos ante la Real Academia de Ciencias... Sucesores de Rivadeneira. Madrid, 1893: en su p. 125)».

20 Sobre la identificación del animal con una divinidad, aspecto que como hemos dicho, menciona Caro Baroja en su comparación con el culto a Dionisos, en lo que Blázquez insiste y también menciona Rodríguez Becerra. 
morras, peropalos, etc. Pero también aparece un mayordomo de cofradía en el rito, generalmente llamando al toro. A veces se explicita ser «una cofradía creada para tal fin» quien llama y "santifica» al animal, pero podría ser una cofradía preexistente, encargadas de tantas cuestiones laterales al culto. Tales mayordomos de cofradías, compuestas por los propios vecinos, campesinos acostumbrados al trato con el animal, justifican una confianza y destreza en su manejo que explica el prodigio de la aparente mansedumbre, conectándola incluso con esa complacencia hacia lo milagrero que medra desde la Contrarreforma como parte de una intención por conectar las creencias populares y transformarlas de acuerdo con los principios del concilio de Trento; se buscaba así una manera de «comulgar» con el gusto popular y transformar creencias paganas o supersticiones mágicas y acercarlas a los preceptos de la Iglesia propios del espíritu de la Contrarreforma ${ }^{21}$. Hay un elemento general a las creencias populares de la Europa medieval y moderna, con raíces en viejas formas de religiosidad, en la que tuvieron un papel esencial de integración cúltica las órdenes mendicantes (Gelaberto Vilagran, 2003: p. 188) que genera un conflicto entre práctica supersticiosa y creencia cristiana. Esto se encuentra ampliamente documentado en la España moderna.

Pero sobre todo, tales personajes e instituciones implican otro nivel social en la fiesta. El papel de las cofradías o hermandades como organizaciones seglares características de la sociedad moderna española que se convierten en organizadoras de una parte de la vida secular - aunque no siempre fuera del todo de la omnipresente Iglesia ${ }^{22}$-, nos sitúa ante un punto de participación entre lo institucional y lo popular de una fiesta que, en realidad puede entenderse también desde una última problemática: tal como nos los presentan algunos de esos documentos, nos encontramos ante otra fiesta del toro, en la que el animal termina por ser lidiado. Se llega así a una serie de festividades y problemas muy comunes, y de otra na-

${ }^{21}$ Rodríguez Becerra (2000), dedica un capítulo donde se refiere a ese gusto por la emulación, incluso antagonismo entre poblaciones en los cultos propios de la religiosidad popular. Sobre su expansión seguimos citando al mismo Rodríguez Becerra (2000: p. 232) «De todo ello podemos deducir que son las gentes devotas que se organizan en cofradías, impulsadas por los frailes y clérigos, las que institucionalizan la procesión y culto al santo; que otras tantas veces es consecuencia de rogativas y votos hechos por los Ayuntamientos de los pueblos en situaciones críticas, con ocasión de epidemias, plagas y sequías, como lo prueban los numerosos casos extraídos del Interrogatorio de la Real Audiencia (1790). Menos frecuente es el caso de declaración del patronazgo del santo. En esta decisión confluyen toda una serie de intereses a los que no son ajenos los grupos de poder civiles y eclesiásticos, con frecuencia enfrentados. Otro factor a tener en cuenta en la difusión de devociones es la influencia de unas poblaciones en otras, como hemos visto en Baeza, Almendralejo y Casas del Monte, en relación con esta última se dice explícitamente que la cofradía «indagó las liturgias que en otros lugares se practicaban con el toro» (citado por M. García Matos: "Curiosa historia del "toro de San Marcos" en un pueblo de la alta Extremadura». Revista de Dialectología y Tradiciones populares, 1948, IV: 600-610. (Incluye el documento «Observaciones críticas sobre el toro de San Marcos» elaborado por el bachiller Lorenzo Miranda, cura párroco de Casas del Monte).

${ }_{22}$ Las cofradías como formas de asociación y convivencia en los pueblos de la España moderna, especialmente importantes sobre todo, en poblaciones mayores de las ciudades modernas, como ha visto el mismo Rodríguez Becerra, incidiendo así mismo en un modelo de organización horizontal de la sociedad (por barrios, patronos o actividades), que difuminaba la vertical de clases (cf. al respecto la obra de Isidoro Moreno Navarro, Cofradías y Hermandades andaluzas: estructura, simbolismo e identidad, Sevilla, 1985, y del mismo autor, Propiedad, clases sociales y hermandades en la Baja Andalucía: la estructura social de un pueblo del Aljarafe, Madrid, Siglo XxI, 1972). 
turaleza: las fiestas con toros, de tanta tradición en nuestro suelo, y que adoptan formas tan variadas, y a las que se han propuesto tantos antecedentes ${ }^{23}$.

La fiesta con el toro, viejo ancestro y todavía pariente vivo de la lidia, es el cauce mayor en el que puede desembocar como caso concreto el culto de San Marcos, de acuerdo con la valoración de esas noticias que tenemos de la fiesta, apartándolo del tema hasta ahora ceñido a la identificación con el santo. Un tema más general, cuyos ecos y concomitancias en el mundo hispano pueden llevar a considerarlo estructural, de cepa remota. Obligada referencia en este punto es la obra de Álvarez de Miranda (1962), quien recogía las propuestas de otros autores de identificar las raíces de la fiesta en el mundo musulmán español, aun anotando la existencia de lidias a caballo en el España cristiana, como la que protagonizaría El Cid y que luego se hicieron muy populares en la corte de los Trastámaras (Juan II y Enrique IV), con preferencia a las que remontaban sus orígenes al mundo romano ${ }^{24}$. No nos entretenemos más en detallar sus apreciaciones, que tras el recorrido por los mitos y las artes tauromáquicas, y sus antecedentes prehistóricos y antiguos, concluyen en tres puntos sobre el valor ritual del toro (Álvarez de Miranda 1962: p. 208 ss.): la identificación del toro con la divinidad —que vendrían a ser los casos propuestos-, el derramamiento de su sangre fecundante, y su «potencia mágica en orden a la generación humana», las cuales, sin embargo, desde aquel lejano 1962, con su autor ya finado, no dejan de resentirse del ineludible paso del tiempo ${ }^{25}$. Tampoco puede dejar de subrayarse lo que ese trabajo contiene de interpretación simbólica, y dejamos por un momento en suspenso la interpretación de Álvarez de Miranda, quien, salvo en las alusiones pertinentes al tema de los festejos nupciales, no se extiende en las variedades de las fiestas con toros (vaquillas, enmaromados), que supedita el autor al toro nupcial y a los significados implícitos en el mismo ${ }^{26}$. Si bien es cierto que en los más antiguos documentos se menciona el manejo del toro en festividades nupciales, cabe preguntarse si la fiesta del toro se limita a ese contexto, o si, por el contrario, se produce una simbiosis más o menos coyuntural. ¿Proceden las fiestas con toros de esa concepción fecundadora, antes de derivar a otros derroteros? ¿O es la fiesta nupcial con toro un caso más de fiesta con toro?

23 Cf. sobre los mismos en A. Álvarez de Miranda (1962).

24 Álvarez de Miranda (1962: nota 65, en su p. 33) se remite a la obra Nicolás Fernández de Moratín (1737-1780), Carta histórica sobre el origen y progresos de las fiestas de toros en España.

25 Todo un cúmulo de importantes trabajos han ido apareciendo sobre el sacrificio animal, Marcel Detienne, The cuisine of sacrifice among the Greeks, Chicago, 1989, Walter Burkert, Homo necans: the anthropology of ancient Greek sacrificial ritual anf myth, Berkeley, 1983, Jean-Louis Durand, Sacrifice et labour en Grèce ancienne: essai d'anthropologie religieuse, La Decouverte, París, 1986. Sin extendernos en propuestas como las de Girard (1983), donde el sacrificio es sublimación de la necesidad de una violencia, violencia dirigida y controlada. Igualmente, sobre el sacrificio del toro en las religiones mistéricas, en particular, en el mitraismo (donde se viene admitiendo que la sangre del toro sacrificado era asperjada sobre los iniciados en un lugar a propósito —el taurobolio-, quedando de esta manera purificados), culto mistérico no explícitamente mencionado por Álvarez de Miranda, pese a la abundancia de sangre en el mismo, han aparecido varias interpretaciones desde el Congreso de Manchester sobre Mitraismo.

26 El título de su obra, Mitos y ritos del toro podría acompañarse de «en relación con la fecundidad». Esos documentos más antiguos a los que se refiere Álvarez de Miranda son los fueros de Zamora. 
La fiesta con el toro da pie a plantear muchas cosas: más allá de lo lúdico del juego, muestra de exhibición, de pericia, incluso de lucha, que no tiene porqué reducirse a los temas simbólicos propuestos por Álvarez de Miranda en su origen. Y remite a otras realidades, económicas, vivenciales: la realidad «estructural» que comentábamos ${ }^{27}$. Se trata, en suma, del manejo y trato con el toro, necesidad de orden económico allí donde existe una ganadería extensiva, marco natural para el desarrollo de una raza de lidia, menos domesticada que otras, donde el animal tiene que ser conducido, acosado, apartado, manejado en determinados momentos. De ese trato imperioso con el toro, animal peligroso, nace el juego con el mismo, donde cuaja un universo simbólico lleno de alusiones, entre ellas la exhibición viril o de dominio y maestría. En el contexto de los esponsales es posible plantear como tema anejo una insinuación a la fecundidad, con la asistencia de la novia. Aunque la alusión procede del peligro reconocido, del mito que se genera alrededor suyo, y no sólo del reconocimiento de sus cualidades fecundantes.

\section{CONCLUSIONES. ¿SUPERVIVENCIAS O ANALOGÍAS?}

Diferentes estudios han incidido en remontar tradiciones y fiestas populares a la más remota antigüedad. Podemos citar unos cuantos ejemplos de investigadores que han propuesto unas raíces primitivas a costumbres o ritos, incluso a relatos más o menos conservados en época moderna ${ }^{28}$, como las fiestas de plenilunio celebradas en Viana del Bollo y documentadas hasta principio de siglo, que se han querido relacionar con las festividades indígenas mencionadas por Estrabón ${ }^{29}$, o las famosas exposiciones en los caminos, documentadas en la Cabrera Baja leonesa, análogas a las citadas por el mismo autor ${ }^{30}$. El calendario agrario se jalona con fiestas de sabor arcano. Las botargas de San Sebastián ${ }^{31}$, y otros seres disfrazados o enmascarados con aspecto teriomórfico, que reciben nombres diversos - carantoñas, jarramplas - fiestas de invierto en las que se pasean unas máscaras, que son bailadas, y que golpean o son golpeadas, con formas similares extendidas

27 Y en la que coinciden otros autores como Moratín (citado en Álvarez de Miranda 1962: p. 33): «Al contrario -afirma Moratín-, las corridas españolas son un fenómeno autóctono y causal. Siendo España un país muy abundante en toros bravos, es natural que desde tiempos muy antiguos se haya ejercitado la habilidad de combatirlos, ya para evitar el peligro de sus ataques, ya para demostrar, frente a ellos, el valor personal, ya para cazarlos y alimentarse de ellos.»); cf. lo ya mentado por Rodríguez Becerra a propósito de la geografía de la fiesta y sus condiciones ecológicas y económicas.

28 Recordemos los innumerables trabajos de Caro Baroja como folclorista, epítome de una tradición menos conocida de estudiosos locales, o Blázquez Martínez para otros estudios que principian en la Antigüedad. Rodríguez Becerra (2000) sobre las mayas; la obra de Álvarez de Miranda (1962), y un largo etc.

${ }_{29}$ Estrabón (III, 3, 16) «Algunos dicen que los calaicos no tienen dioses, y que los celtíberos y sus vecinos del norte hacen sacrificios a un dios innominado, de noche en los plenilunios, ante las puertas, y que con toda la familia danzan y velan hasta el amanecer.», trad. M. a José Meana y Félix Piñero, ed. Gredos, Madrid, 1992. Caro Baroja (1981: p. 169). También Blázquez Martínez (1983: pp. 238-9), remitiéndose de nuevo a Caro Baroja (1977: pp. 86 y 238).

30 Estrabón (III, 3, 7) «A los enfermos, como antiguamente los egipcios, los exponen en los caminos

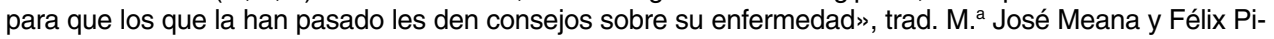
ñero, ed. Gredos, Madrid, 1992. Caro Baroja (1981: p. 169 y ss). y Blázquez Martínez (1983: p. 302).

${ }_{31}$ Algo al respecto entre una muy abundante bibliografía en Caro Baroja (19882: pp. $\left.115 \mathrm{ss}\right)$. 
hasta los más remotos lugares de las montañas mediterráneas, desde Grecia hasta la Península ibérica, no dejan de presentar cierta coincidencia con los lupercales celebrados en Roma ${ }^{32}$, y en cualquier caso, no se puede negar su sabor arcano. Por no hablar de la multitud de rituales que pudieran reproducir elementos comunes en las fiestas de San Juan, en las diferentes de mayo, etc. Rodríguez Adrados (1983: p. 513 ss) en su estudio de los orígenes de la tragedia, se detiene en revisar algunas conexiones entre ritual y teatro fuera de Grecia, y pone como ejemplo diferentes casos de fiestas de solsticio o equinoccio absorbidas por las fiestas cristianas; en particular, las del Corpus, las mayas, las de San Jorge, ejemplificando casos varios de motivos y variantes. Su perspectiva es, precisamente, examinar los géneros teatrales en conjunto - Tragedia, Drama Satírico, Comedia- para ver lo que tienen en común.

Las perspectivas de los estudiosos de la cultura popular medieval y moderna han abierto un espacio cada vez mayor a las supervivencias religiosas de una cultura popular primitiva, de raíces indoeuropeas o antiguas, con determinados barnices musulmanes en ciertos casos. Gelaberto Vilagran (2003: p. 18), nos presenta escuetamente el panorama remitiéndose a los estudios de Carlo Ginzburg y Gustav Henningssen, quienes plantean la supuesta continuidad en el tiempo de formas paganas de religiosidad de culturas antiguas, sin conexión con el cristianismo oficial, cuyos ejemplos más significativos corresponderían a la práctica de ciertos cultos agrarios de la fecundidad, todavía en pleno vigor en la Europa meridional del siglo XVI, mientras más adelante, recuerda como Christian y Jean Claude Schmitt rechazan abiertamente la posibilidad de pervivencias de estratos culturales paganos en las conciencias de las poblaciones rurales preindustriales europeas. Así Schmitt (en Gelaberto Vilagran 2003: p. 20) piensa que todo ello forma parte de un proceso de asimilación cultural de profunda cohesión interna donde la forma oficial de la doctrina cristiana y la forma popular del cristianismo no están separados ni son independientes el uno respecto del otro. El cristianismo deviene entonces una religión popular. Por otra parte, los estudiosos del tema de la religiosidad popular $^{33}$, entienden que la cristianización en muchos ámbitos populares era superficial.

Las cuestiones sobre continuidad de las tradiciones, sobre la transmisión de temas míticos, o ritos, como el mostrado para el caso del Toro de San Marcos, adquieren, tras esta última comparación entre documentos antiguos y modernos, no una entidad que defina claramente una supervivencia, al faltar eslabones de momento indocumentables, pero sí un nueva posición para contemplar el problema. Así, el milagro del toro de San Marcos se abre a otras muchas cuestiones, al tiem-

32 Recordemos algunos de los puntos básicos de los lupercales: se trata también de unas festividades del ciclo de invierno (se celebraban en febrero), documentadas no sólo en Roma, sino también en otros lugares próximos, y que consistían también, entre otras cosas, en un recorrido realizado por los miembros de la cofradía (lupercos) que corrían vestidos solamente con pieles de cabras y tocados por coronas, supuestamente a imagen de Fauno, que golpeaban a quien se cruzaba en su camino dando latigazos (Cf. al respecto en Guillén 1985: pp. 196 ss.).

33 Gelaberto Vilagran (2003: p. 5), remitiéndose a Mandrou (1966) y Baktin (1971) y luego a Jean Delumeau (1965 y 1971). 
po que, adecuadamente contextuado, se ubica mejor dentro de un sistema de fiestas en el que queda prendido. La fiesta del toro de San Marcos se celebra en muchos lugares, algunos entre tantos otros donde el toro debe ser manejado como parte de una actividad ganadera más o menos desarrollada. Pero tampoco exclusivamente, puesto que según vimos, junto a una geografía coherente con las dehesas, hay fenómenos de expansión del culto por emulación hacia lugares distantes. Ese manejo, que en ocasiones produce fiesta, se hace en la festividad de San Marcos cristianamente, con la ayuda del mediador sagrado por antonomasia del ambiente rural: el cura, que sacraliza ese acto en el contexto de la fiesta. Entonces, identificado el animal con el santo se produce el milagro. Así lo ven los franciscanos. Pero no todos ven prodigio. Otros ven fiesta, actos paganos, como se ha mostrado. En otras ocasiones son los mayordomos de las cofradías o hermandades, posiblemente gente avezada en el manejo del ganado. Sin duda hay un auxilio terrenal y laico: la pericia de esos mayordomos de hermandades, cabezas visibles de un orden social campesino, cabe suponer que en muchos casos gentes experimentadas en esas suertes, capataces o mayorales. Así guiado el toro, es paseado (no se nos dice si precavidamente sujeto con cuerdas en algunos casos, como en tantos otros juegos de toro enmaromados, y de la misma manera como se celebra en Ohanes), incluso introducido en casas y en la misma Iglesia. Pero también se cede al gusto popular, y se le lidia; incluso, ocasionalmente, se le mata y es consumido en una fiesta, como refiere otra noticia de que, una vez lidiado, su carne se repartía ${ }^{34}$, lo que nos lleva al asunto de una redistribución alimentaria, que queremos subrayar, destacándolo junto a aspectos como el comensalismo - donde se facilitan las relaciones sociales, punto en el que han insistido una larga serie de estudiosos desde una perspectiva sociológica y antropológica ${ }^{35}$; o incluso más vitales, donde se da un aprovechamiento de la proteína nutricia - no podemos dejar de evocar aquí a Marwin Harris en su célebre Vacas, cerdos, guerras y brujas-. No desarrollamos estos otros aspectos laterales a la fiesta del toro de San Marcos, pero tampoco queremos dejar de mencionarlas. Por ejemplo, uno de los puntos de la descripción del padre Feijoo toca al trato de las mujeres, quienes lo engalanan con guirnaldas, y nos remite de nuevo a las hipótesis de Álvarez de Miranda sobre el simbolismo fecundador del animal.

Todo ello remite a una realidad estructural. Recordemos cuando el mismo Caro Baroja (1991: p. 183) ${ }^{36}$, señalaba la fiesta de San Marcos (el 25 de abril) como el comienzo de los movimientos pastorales, iniciando el ciclo de mayo,

34 «Excepcionalmente, el animal era lidiado y sacrificado como parte de la ceremonia dedicada a San Marcos y su carne repartida entre los pobres.» (Rodríguez Becerra 2000: p. 219).

35 Recordemos especialmente a Marcel Mauss, y para la Antigüedad a autores como W. Burkert, o Versnel, cf. supra. nota 25 para estas referencias.

36 Cf. también Rodríguez Becerra (2000: p. 221), ya citado, donde comenta la relación entre la fiesta con las Robigalia, y «Con la fiesta y procesión de San Marcos se pretendía conseguir, entre otros objetivos, como antes se hiciera entre los romanos antiguos, la protección para las cosechas y animales y Iluvia mediante rogativas; se consideraba, así mismo, que en esta fecha terminaba el invierno y comenzaba el verano -en una concepción dual del año, propia de agricultores y ganaderos-, y era, por tanto, el momento de hacer ciertas siembras; se tomaba así mismo su fiesta como inicio del cálculo sobre las predicciones de lluvia para el año, las denominadas "cabañuelas"». 
«mes de las fiestas y expansiones amorosas». Si la fiesta se celebra en muchos sitios como parte de unas fiestas agrarias, precisamente esas zonas donde se documenta el rito con toro son, a menudo, aquellas donde se han conservado reses de lidia y donde el trato de las mismas es un elemento más de la vida económica. Se trata de unos ritos celebrados en momentos y lugares donde determinadas actividades pastoriles tienen una importancia capital, donde el manejo del ganado es un elemento económico esencial y donde el símbolo (tal como lo ha presentado Álvarez de Miranda) sigue jugando difuso pero evocador. ¿Cuáles son sus orígenes? ¿Hasta donde se pueden remontar? El trabajo de Rodríguez Becerra, obra de un antropólogo y folclorista que muestra ser a la vez buen conocedor del mundo moderno, rastrea las condiciones de la fiesta, aportando un monto de noticias que añade a la posibilidad de una supervivencia para conducirlo por un mundo de realidades más próximas. Pero tampoco se niega esta posibilidad. Allí principiaba el mismo Rodríguez Becerra, en las Robigalia, aunque es en las raíces medievales del mundo moderno donde más claramente pueden encontrarse los antecedentes inmediatos de la fiesta ${ }^{37}$. Ahí queda de momento el tema, en esa ambigüedad, donde no es posible determinar un origen, ni negarlo tajantemente.

\section{BIBLIOGRAFÍA}

ALARCÂO, J. (1989), «Geografía política y religiosa da civitas de Viseu», Actas do I Coloquio Arqueologico de Viseu, Viseu, pp. 305-314.

ALBERTOS, M. L. (1977), «Perduraciones indígenas en la Galicia romana: los castros, las divinidades y las organizaciones gentilicias en la epigrafía», Actas del Coloquio Internacional sobre el Bimilenario de Lugo, Lugo, pp. 17-27.

ALBERTOS, M. L. (1985), «A propósito de algunas divinidades lusitanas (Arantius Ocelaecus, Arantia Ocelaeca) y el elemento ocelum», Symbolae Ludovico Mitxelena septuagenario oblatae, Vitoria, pp. 469-494.

ÁLVAREZ DE MIRANDA, A. (1962), Ritos y juegos del toro, Taurus, Madrid.

BAKTIN, M., (1971) La cultura popular en la Edad Media y el Renacimiento, Barcelona.

BLANCO, A. (1959), «Pátera argêntea com representaçâo de una divindade lusitana», $R e-$ vista de Guimaraes 69, p. 453.

BLÁZQUEZ MARTíNEZ, J. M. (1983), Primitivas religiones ibéricas, tomo II, Religiones Prerromanas, Cristiandad, Madrid.

BLÁZQUEZ MARTÍNEZ, J. M. (1986), «Sincretismo en la Lusitania romana», Primeras Jornadas sobre manifestaciones religiosas en Lusitania, Cáceres, pp. 7-14.

CARO BAROJA, J. (1977), Los pueblos del norte de la Península ibérica, San Sebastián.

CARO BAROJA, J. (1981), Los pueblos de España, II, Istmo, Madrid.

CARO BAROJA, J. (1988²), Estudios sobre la vida tradicional española, Barcelona.

CARO BAROJA, J. (1991), Los pueblos de la Península ibérica. Temas de etnografía española, Crítica, Barcelona.

CHRISTIAN, WILIAM, A. (1991), Religiosidad local en la España de Felipe II. Nerea. Madrid.

37 Rodríguez Becerra (2000: nota 40, p. 225): «Las celebraciones en honor de San Marcos, que al parecer se extendieron por España con cierto retraso, llegaron a ser muy importantes en algunas regiones: ya el Arcipreste de Hita en su libro de Buen Amor (1330-1343), refiere en unos versos que la fiesta y procesión de San Marcos es una de las mayores del año». 
DE HOZ, J. (1986), «La religión de los pueblos prerromanos de Lusitania», Primeras Jornadas sobre manifestaciones religiosas en Lusitania, Cáceres, pp. 31-49.

DÜRRBACH (1911), «Mars» en Dictionnaire des antiquités grecques et romaines, III/2, p. $16 x t x t-$.

GELABERTO VILAGRAN, M. (2003), La palabra del predicador. Contrarreforma y superstición en Cataluña (siglos XVII-XVIII), Universidad Autónoma de Barcelona, Tesis doctoral, formato pdf.

GIRARD, RENÉ (1983), La violencia y lo sagrado, Editorial Anagrama, Barcelona.

GUILLÉN, JOSÉ (1985), Urbs Roma, III, Religión y ejército, Sígueme, Salamanca.

HILD, J.-A. (1911), «Robigus, Robigalia» en Dictionnaire des antiquités grecques et romaines, IV/2, p. 874-5.

MANDROU, R., (1966), De la culture populaire aux XVIle et XVIIle siècles: la bibliotheque bleu de Troyes, París.

OLIVARES PEDREÑO, J. C. (1997), «El dios indígena «Bandua» y el rito el toro de San Marcos», Complutum n. ${ }^{\circ}$ 8, pp. 205-221.

OLIVARES PEDREÑO, J. C. (2002), Los dioses de la Hispania céltica, Real Academia de la Historia, Madrid.

RODRÍGUEZ ADRADOS, FRANCISCO (1983), Fiesta, comedia y tragedia, Alianza, Madrid.

RODRÍGUEZ BECERRA, SALVADOR (2000), Religión y fiesta. Antropología de las creencias y rituales en Andalucía, Signatura Ediciones de Andalucía, Sevilla.

SCHMITT, JEAN CLAUDE (1976), «Religion populaire et culture folklorique», Annales, 5, pp. 941-953.

SCHMITT, JEAN CLAUDE (2001), Le corps, les rites, les rêves, le temps. Essais d'anthropologie médiévale, Paris. 